\title{
Spiral suspension, a novel repair technique for severe functional tricuspid regurgitation
}

Kiyoyuki Eishi, MD, Takashi Miura, MD, Ichiro Matsumaru, MD, Kazuyoshi Tanigawa, MD, and Kikuko Obase, MD, Nagasaki, Japan

From the Department of Cardiovascular Surgery, Nagasaki University Hospital, Nagasaki, Japan.

Disclosures: Authors have nothing to disclose with regard to commercial support.

Received for publication Sept 6, 2017; revisions received Dec 31, 2017; accepted for publication Jan 16, 2018; available ahead of print March 9, 2018.

Address for reprints: Kikuko Obase, MD, Department of Cardiovascular Surgery, Nagasaki University Hospital, 1-7-1 Sakamoto, Nagasaki 852-8501, Japan (E-mail: kobase@ nagasaki-u.ac.jp).

J Thorac Cardiovasc Surg 2018;156:649-52

$0022-5223 / \$ 36.00$

Copyright (C) 2018 by The American Association for Thoracic Surgery

https://doi.org/10.1016/j.jtcvs.2018.01.082

- Video clip is available online.

In patients with severely tethered leaflets, repair with ring annuloplasty alone results in residual or recurrent tricuspid regurgitation (TR). ${ }^{1}$ Accordingly, our team has developed a technique that we call "spiral suspension" as a novel approach to papillary muscle (PM) relocation.

Various terminologies are used for the 3 leaflets in the tricuspid valve, 2,3 but they should be described as anterosuperior, septal, and inferior leaflets because they

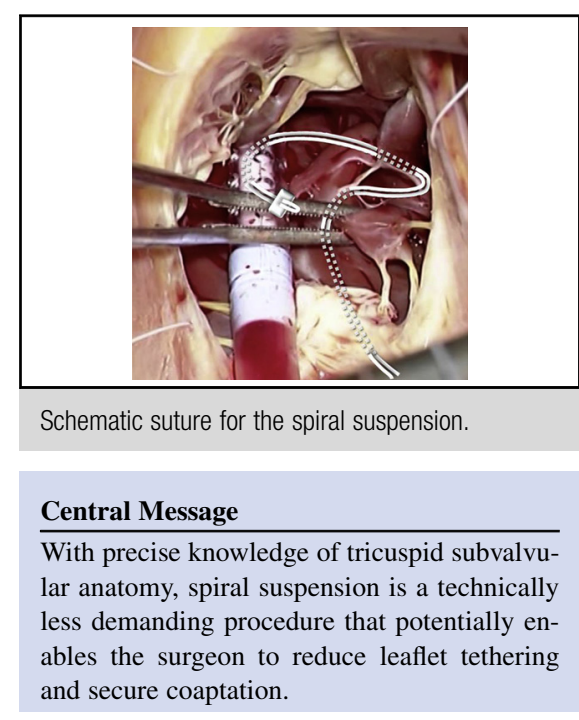

See Editorial Commentary page 653.

See Editorial page 647.

are located within the body. ${ }^{2}$ In our procedure, the anterior PM, the accessory PM for the inferior leaflet (accessory inferior PM), and the inferior PM were approximated and

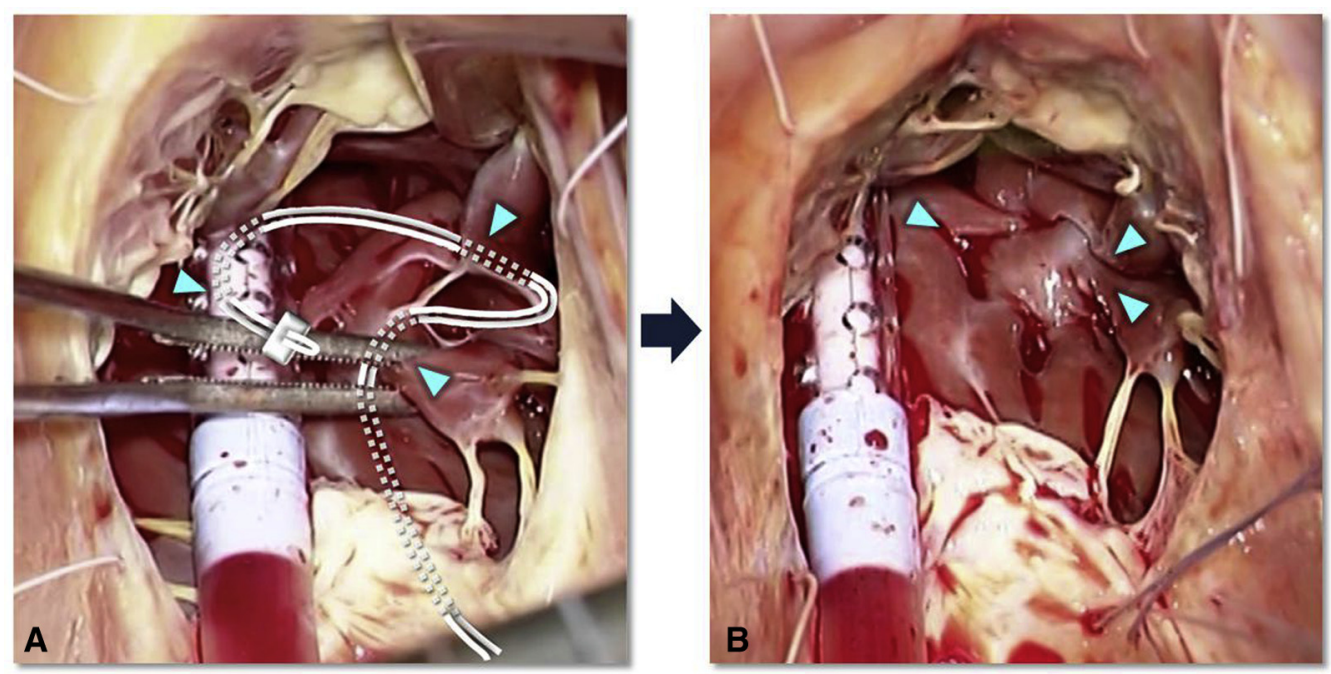

FIGURE 1. A, Schematic suture is depicted. Inferior papillary muscle is being held by forceps. The anterior papillary muscle is visualized on the left side; the accessory inferior papillary muscle is visible to its right, and the inferior papillary muscle is located at the top. Blue triangles indicate the root of each papillary muscle. B, The image on the right shows approximated papillary muscle roots. 


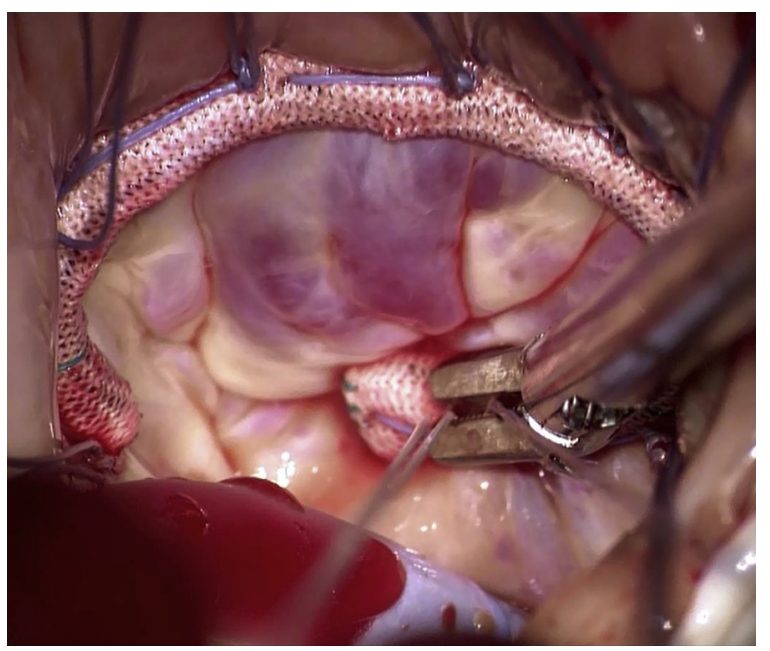

VIDEO 1. Intraoperative video. Minimally invasive right thoracotomy incision surgery under a microscope view. Video available at: http:// www.jtcvsonline.org/article/S0022-5223(18)30358-1/fulltext.

suspended as follows. With the patient under cardiac arrest, before the annuloplasty, 4-0 pledgeted polytetrafluoroethylene suture was placed at the base of anterior PM. Then, in a clockwise fashion, the base of the accessory inferior PM and that of inferior PM were continuously sutured by each arm. The arms were passed into the interventricular septum and then exteriorized onto the septal annulus at the right atrium (Figure 1). The distance between the anterosuperior-septal and the septal-inferior leaflet commissures was used to decide the ring size. After annuloplasty with a 3-dimensional incomplete rigid ring, the polytetrafluoroethylene sutures were passed through the ring. The adjustment of the suture length was performed under a saline solution test, and the sutures were then tied (Video 1).

\section{SURGICAL RESULTS}

From 2015 to 2016, spiral suspension was performed for 7 patients with severe functional TR (age,
$74 \pm 9$ years; 5 male). Preoperatively, the annular diameter at diastole, the end-diastolic right ventricular diameter, and both tenting height and area at midsystole were obtained from the apical 4-chamber view by 2dimensional transthoracic echocardiography (TTE). Tenting height was measured as the maximum distance between the annular plane and the leaflet surface; tenting area was measured as the enclosed area between the annular plane and the leaflet surface. These measurements are summarized in Table 1. It has been reported that tenting height greater than $5.1 \mathrm{~mm}$ or tenting area greater than $0.8 \mathrm{~cm}^{2}$ predicts at least moderate TR after annuloplasty. ${ }^{1}$ As the indication for spiral suspension, these values were referred. Isolated spiral suspension was performed in 3 cases (Table 1, cases 1, 2, and 6). Concomitant procedures were mitral repair in 2 (Table 1, cases 5 and 7), mitral repair plus aortic valve replacement in 1 (Table 1, case 3 ), and atrial septal defect closure in 1 (Table 1, case 4). After the surgery, leaflet tethering was effectively repaired, and postoperative tenting height and area were no longer measurable because they were almost zero in all patients. During the $12.2 \pm 6.8$ months of follow-up, 1 patient (case 7) died 34 days after the surgery of severe liver dysfunction. In this patient, mild to moderate residual TR had been observed on the last TTE. In the other 6 patients, TR was well controlled, with a reduction in right ventricular size (from $40.8 \pm 5$ to $27.3 \pm 3.3 \mathrm{~mm}$ ) and a reduction in pulmonary artery systolic pressure estimated by TTE (from $51.0 \pm 9.1$ to $30.2 \pm 7.9 \mathrm{~mm} \mathrm{Hg}$ ). In cases 1 through 6, recent New York Heart Association functional class was I (cases 1, 3, 4, and 5) or II (cases 2 and 6), and more than mild residual TR was not observed on the recent (14 \pm 5 postoperative months) TTE.

Preoperative and postoperative tricuspid complex visualized by 3-dimensional transesophageal echocardiography with a transgastric approach in case 4 are shown in Figures 2 and 3. The volume rendering images demonstrated the subvalvular apparatus in detail (Figure 2 and

TABLE 1. Clinical summaries

\begin{tabular}{|c|c|c|c|c|c|c|c|c|c|c|c|c|c|}
\hline \multirow[b]{2}{*}{ Case } & \multirow[b]{2}{*}{$\begin{array}{l}\text { Age } \\
(y)\end{array}$} & \multirow[b]{2}{*}{ Sex } & \multirow[b]{2}{*}{ BSA $\left(\mathbf{m}^{2}\right)$} & \multirow[b]{2}{*}{$\begin{array}{c}\text { Preop } \\
\text { LVDd }(\mathbf{m m})\end{array}$} & \multirow[b]{2}{*}{$\begin{array}{c}\text { Preop } \\
\text { LVEF (\%) }\end{array}$} & \multirow[b]{2}{*}{$\begin{array}{c}\text { Preop TV annular } \\
\text { diameter }(\mathbf{m m})\end{array}$} & \multirow{2}{*}{$\begin{array}{c}\text { Selected } \\
\text { ring } \\
\text { size }(\mathbf{m m})\end{array}$} & \multicolumn{2}{|c|}{ RV diameter $(\mathbf{m m})$} & \multicolumn{2}{|c|}{ Preop tenting } & \multicolumn{2}{|c|}{$\begin{array}{c}\text { Estimated } \\
\text { PAP }(\mathbf{m m ~ H g})\end{array}$} \\
\hline & & & & & & & & Preop & Postop & $\begin{array}{c}\text { Height } \\
(\mathbf{m m})\end{array}$ & $\begin{array}{l}\text { Area } \\
\left(\mathrm{cm}^{2}\right)\end{array}$ & Preop & Postop \\
\hline 1 & 82 & $F$ & 1.5 & 42 & 55 & 41 & 26 & 38 & 23 & 5.2 & 1.4 & 48 & 23 \\
\hline 2 & 79 & M & 1.7 & 53 & 70 & 43 & 26 & 34 & 29 & 4.5 & 2.2 & 62 & 44 \\
\hline 3 & 82 & M & 1.4 & 49 & 78 & 40 & 26 & 36 & 29 & 5.7 & 2.4 & 47 & 36 \\
\hline 4 & 60 & M & 1.9 & 41 & 67 & 47 & 28 & 50 & 33 & 7.8 & 1.8 & 60 & 22 \\
\hline 5 & 60 & M & 1.6 & 47 & 63 & 48 & 28 & 47 & 25 & 9.5 & 3.1 & 54 & 25 \\
\hline 6 & 77 & M & 1.6 & 48 & 65 & 44 & 26 & 38 & 25 & 8.1 & 2.6 & 35 & 31 \\
\hline 7 & 79 & $\mathrm{~F}$ & 1.5 & 42 & 72 & 38 & 26 & 42 & 43 & 6.1 & 1.4 & 51 & 52 \\
\hline
\end{tabular}

Mean follow-up period was $12.2 \pm 6.8$ months. $B S A$, Body surface area; Preop, preoperative; $L V D d$, left ventricular diastolic dimension; $L V E F$, left ventricular ejection fraction; $T V$, tricuspid valve; $R V$, right ventricle; Postop, postoperative; $P A P$, systolic pulmonary artery pressure. 


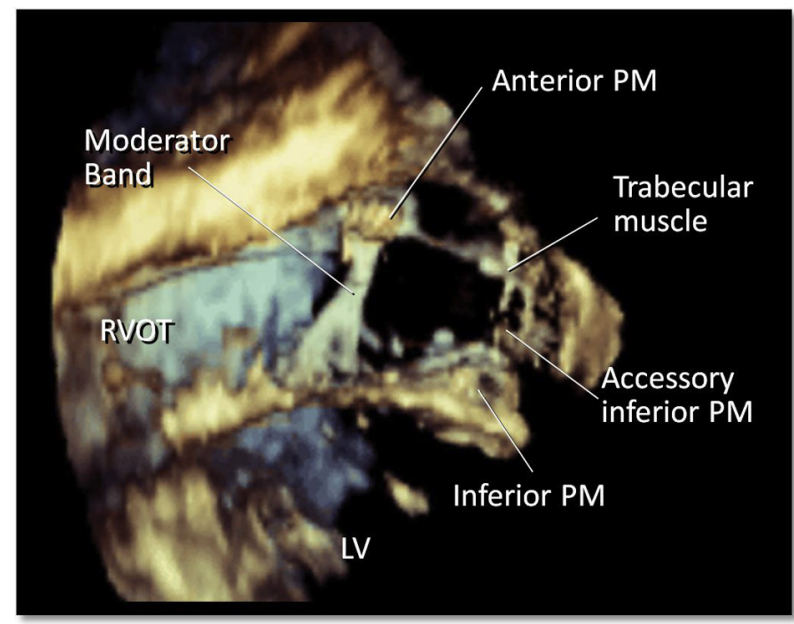

FIGURE 2. Subvalvular apparatus in diastole visualized in volume rendering image by 3-dimensional transesophageal echocardiography with transgastric approach. $P M$, Papillary muscle; $R V O T$, right ventricular outflow tract; $L V$, left ventricle.

Video 2). Reconstructed preoperative and postoperative 3dimensional images by dedicated software (Real View, Nara, Japan) depicted the effectiveness of the spiral suspension by demonstrating postoperative elimination of tethering and decreased distances between the PM tips and the annulus (Figure 3).

\section{Pre-op}
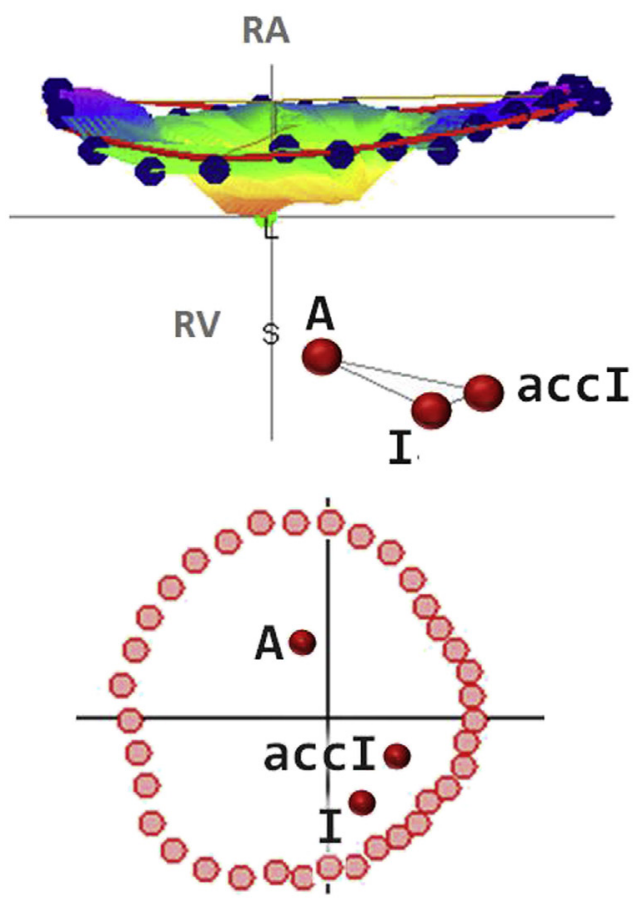

\section{DISCUSSION}

The mechanism of recurrent TR after annuloplasty is associated with leaflet tethering, which is basically the same as that in mitral valve. Unlike in the mitral valve, however, which has PMs tightly connected to the left ventricle, PMs in the tricuspid valve are connected to ventricle wall by

\section{Post-op}
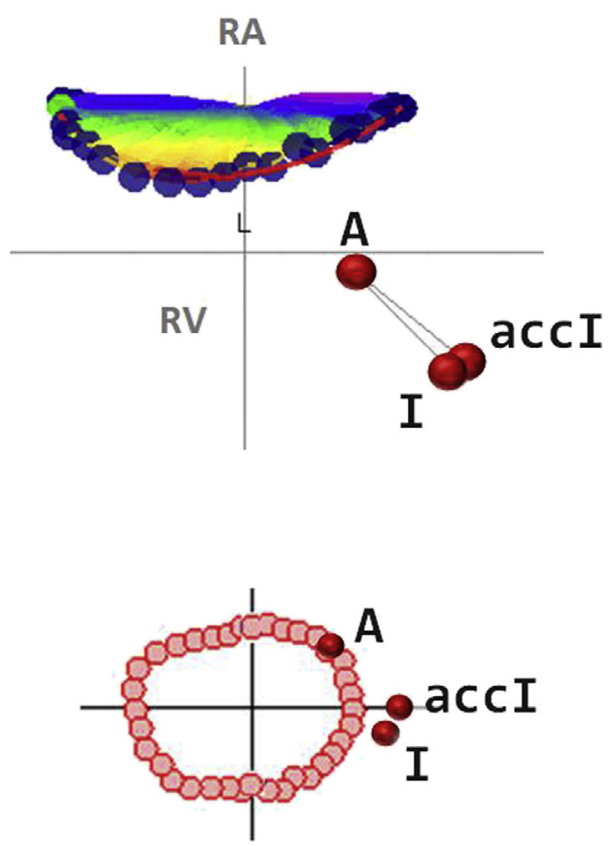

FIGURE 3. Preoperative (Pre-op) and postoperative (Post-op) reconstructed tricuspid valve images in midsystole are shown. Upper images show tricuspid leaflet, annulus, and papillary muscle tips. Lower images show projected annulus and papillary muscle tips from the right atrial $(R A)$ perspective. $R V$, Right ventricle; $A$, tip of the anterior papillary muscle; $I$, tip of the inferior papillary muscle; accI, tip of the accessory inferior papillary muscle. 


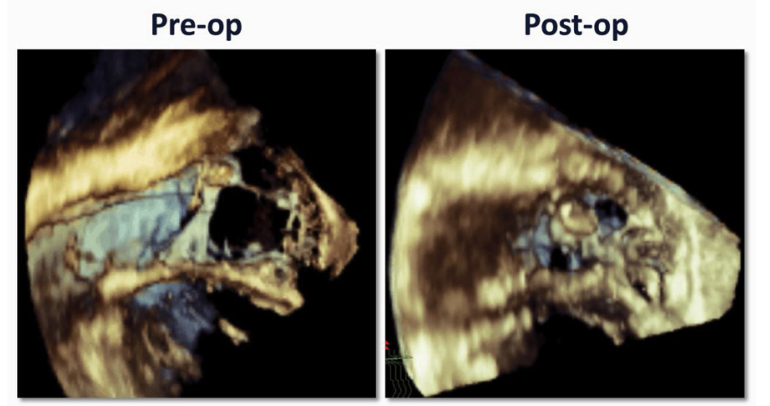

VIDEO 2. Preoperative (Pre-op) and postoperative (Post-op) volume rendering images. Video available at: http://www.jtcvsonline.org/article/ S0022-5223(18)30358-1/fulltext.

loose trabeculation in a low-pressure ventricle. This allows PM approximation and suspension with less stress and tension than in the mitral valve. With our technique, apically and radially shifted PMs are expected to be approximated effectively and suspended toward the midseptal annulus by means of a simple spiral suture, which eliminates leaflet tethering and therefore prevents the recurrence of TR after annuloplasty. Although patients with an aberrant or fragile subvalvular structure might be excluded from the indication for the procedure, we have not seen any such cases to date.

With a precise understanding of the tricuspid subvalvular anatomy, spiral suspension is a technically less demanding procedure that potentially enables the surgeon to reduce leaflet tethering and secure leaflet coaptation. Further investigation is warranted to confirm the effectiveness of the spiral suspension for severe functional TR.

\section{References}

1. Fukuda S, Song JM, Gillinov M, McCarthy PM, Daimon M, Kongsaerepong V, et al. Tricuspid valve tethering predicts residual tricuspid regurgitation after tricuspid annuloplasty. Circulation. 2005;111:975-9.

2. Wilcox BR, Cook AC, Anderson RH. Surgical Anatomy of the Heart. 3rd ed. Cambridge, UK: Cambridge University Press; 2004:65-8.

3. Carpentier A, Adams DH, Filsoufi F. Reconstructive Valve Surgery. 1st ed. St Louis: Elsevier; 2010:178-80. 